\section{THU0028 TYPE I INTERFERON SIGNATURE IN THE PERIPHERAL BLOOD AND CXCL4 PLASMA LEVELS IN PATIENTS WITH SYSTEMIC SCLEROSIS}

N.I. Vlachogiannis, V.-K. Bournia, A. Nezos, P.F. Christopoulos, M. Patsouras, P.G. Vlachoyiannopoulos, C.P. Mavragani, P.P. Sfikakis. Joint Academic Rheumatology Program, National and Kapodistrian University of Athens Medical School, Athens, Greece

Background: Type I Interferon (IFN) pathway is activated in Systemic Sclerosis (SSc) and represents a therapeutic target currently being tested in clinical trials, while higher IFN $\alpha$ levels have been also associated with pulmonary fibrosis in these patients. On the other hand, in vitro experiments using plasmacytoid dendritic cells from patients with SSc suggest an interplay between the chemokine (C-X-C motif) ligand 4 (CXCL4), a potential biomarker in SSc, and type I IFN. [1] Objectives: To test the hypothesis that type I IFN-induced gene expression in the peripheral blood associates with particular clinical and laboratory features, including plasma CXCL4 levels, in patients with SSc.

Methods: Forty six patients with limited and 19 with diffuse SSc (60/65 women, aged $54 \pm 14$ years, disease duration ranging between $0.5-27$ years) and 20 healthy controls were examined. Peripheral whole blood samples $(3 \mathrm{ml})$ were subjected to cDNA synthesis and the expression of 3 genes (IFIT1, MX1, IFI44) that are preferentially induced by type I IFN was quantified by real time PCR. Type I IFN individual scores were calculated as described [2]; scores were arbitrarily considered as high when exceeding the mean value plus 3SD of the corresponding healthy control scores. Plasma CXCL4 levels were determined by ELISA.

Results: A high type I IFN score (i.e. $>8$ ) ranging from 8.4 to 145 was found in $21 / 65(32.3 \%)$ patients with SSc, compared with none of 20 healthy controls (p:0.002). SSc patients with high type I IFN scores demonstrated higher erythrocyte sedimentation rate and lower diffusing lung capacity for carbon monoxide (DLCO) levels than the remaining patients ( $p: 0.002$ and p:0.02, respectively, by Mann-Whitney $U$ test). Other disease variables, including extent of skin involvement and autoantibodies, were not associated with high type I IFN score. Individual type I IFN scores positively correlated with the corresponding CXCL4 plasma levels (Spearman's r: 0.53, p-value: 0.02).

Conclusions: A prominent type I IFN signature was observed in the peripheral blood of one third of patients with SSc in association with upregulated inflammatory response, reduced DLCO levels and higher CXCL4 plasma levels. Further prospective data are required to establish the role of type I IFN as an additional novel biomarker in SSc.

\section{References:}

[1] van Bon L, Affandi AJ, Broen J, et al. Proteome-wide analysis and CXCL4 as a biomarker in systemic sclerosis. N Engl $\mathrm{J}$ Med 2014;370:433-43. doi:10.1056/NEJMoa1114576.

[2] Nezos A, Gravani F, Tassidou A, et al. Type I and II interferon signatures in Sjogren's syndrome pathogenesis: Contributions in distinct clinical phenotypes and Sjogren's related lymphomagenesis. J Autoimmun 2015;63:47-58. doi:10.1016/j.jaut.2015.07.002.

Disclosure of Interest: None declared

DOI: 10.1136/annrheumdis-2017-eular.4066

\section{THU0029 BACTERICIDAL/PERMEABILITY-INCREASING PROTEIN DOWNREGULATES THE INFLAMMATORY RESPONSE TO PATHOGENIC CRYSTALS IN VITRO AND IN VIVO}

A. Scanu ${ }^{1}$, R. Luisetto ${ }^{2}$, F. Oliviero ${ }^{1}$, P. Galozzi ${ }^{1}$, R. Ramonda ${ }^{1}$, L. Punzi ${ }^{1}$ ${ }^{1}$ Rheumatology Unit, Dept. of Medicine, University of Padova; ${ }^{2}$ Dept. of Surgical Oncological and Gastroenterological Sciences, Padova, Italy

Background: Bactericidal/permeability-increasing protein (BPI) is a cationic protein mainly produced by polymorphonuclear cells (PMN) which exerts an antimicrobial activity by damaging bacterial membranes and interacts with specific cell surface receptors, such as toll-like receptors (TLRs). BPI has been detected in synovial fluid of patients with different arthritis, including crystal-induced arthritis. Objectives: To evaluate the effects and mechanisms of action of BPI in in vitro and in vivo models of crystal-induced inflammation.

Methods: The human monocytic cell line THP-1 was primed for $3 \mathrm{~h}$ with phorbole myristate acetate $(300 \mathrm{ng} / \mathrm{ml})$, reincubated overnight, and treated with sterile synthetic monosodium urate (MSU) $(0.5 \mathrm{mg} / \mathrm{ml})$ or calcium pyrophosphate (CPP) $(0.1 \mathrm{mg} / \mathrm{ml})$ crystals for $24 \mathrm{~h}$ in presence or absence of BPI $(5 \mu \mathrm{g} / \mathrm{ml})$. In some experiments, cells or crystals were pretreated with BPI for $2 \mathrm{~h}$ before stimulation. BPI inhibition experiments were carried out with antibody against TLR2 or TLR4. Cell supernatants were tested by ELISA for interleukin (IL)-1 $\beta$ and IL- 8 production. Chemotactic effect of culture supernatants was evaluated in chemotaxis chamber by the migration of freshly isolated peripheral blood PMN.

As regard the study in vivo, air pouches were raised on the backs of CD1 mice ( $n=7$ per condition). $2 \mathrm{mg}$ of MSU crystals in $1 \mathrm{ml}$ of PBS were injected into the pouch in the presence or absence of $0.1 \mathrm{mg}$ of $\mathrm{BPI}$ for $3 \mathrm{~h}$. Controls received 1 $\mathrm{ml}$ of PBS. After the sacrifice, pouch fluids were recovered by washing with $2 \mathrm{ml}$ of PBS. Leukocyte count in lavage fluids was obtained using a hemocytometer and the percentage of PMN was determined by May-Grünwald-Giemsa staining. IL-1 $\beta$, chemokine (C-X-C motif) ligand 1 (CXCL1) and IL-6 levels were measured in exudates by ELISA.
Results: Exposure of THP-1 cells to different types of crystals increased the production of IL-1 $\beta$ (MSU: $406.62 \pm 12.00 \mathrm{pg} / \mathrm{ml}$; CPP: $357.07 \pm 25.17 \mathrm{pg} / \mathrm{ml}$ ) and IL-8 (MSU: $3798.56 \pm 24.64 \mathrm{pg} / \mathrm{ml}$; CPP: $3427.74 \pm 22.33 \mathrm{pg} / \mathrm{ml}$ ). The release of both cytokines induced by crystals was significantly diminished in the presence of BPI ( $76 \% \mathrm{IL}-1 \beta, 58 \% \mathrm{IL}-8)$, and tended to be more pronounced when cells, but not crystals, were pretreated with the protein (90\% IL-1 $1,65 \%$ IL-8). The presence of antibody anti-TLR2 or anti-TLR4 did not affect the BPI inhibitory effect. Supernatants of crystal-stimulated cells increased the migration of PMN cells which was reduced in the presence of BPI.

The injection of MSU crystals into the subcutaneous pouches of mice induced leukocyte infiltration $\left(10.2 \pm 3.39 \times 10^{5}\right.$ cells $\left./ \mathrm{ml}\right)$ comprising $68.6 \pm 8.75 \%$ of $\mathrm{PMN}$. IL-1 $\beta(32.33 \pm 6.35 \mathrm{pg} / \mathrm{ml}), \mathrm{CXCL} 1(467.07 \pm 27.47 \mathrm{pg} / \mathrm{ml})$ and IL-6 $(624.61 \pm 29.41$ $\mathrm{pg} / \mathrm{ml}$ ) were measured in lavage fluids. The co-injection of MSU crystals and BPI inhibited leukocyte influx by $60 \%$ and PMN infiltration by $87 \%$ and, in turn, the levels of all assessed cytokines were reduced (81\% IL-1 $\beta, 70 \%$ CXCL1, 35\% IL-6).

Conclusions: This study shows that BPI reduces the crystal-induced inflammatory process in vitro and in vivo by inhibiting pro-inflammatory cytokine release and PMN recruitment. The mechanism of action of $\mathrm{BPI}$ may include the direct interaction with activated cells in a TLR-independent manner.

Disclosure of Interest: None declared

DOI: 10.1136/annrheumdis-2017-eular.4865

\section{THU0030 IL-2IC SUPPRESSES CIA IN MICE BY THE TH1/TH17 IMMUNE RESPONSES DUE TO ENHANCEMENT OF BOTH TREG NUMBERS AND TREG FUNCTIONS}

Y. Yokoyama ${ }^{1}$, T. Imasaki ${ }^{2}$, S. Kitano ${ }^{1}$, T. Furukawa ${ }^{1}$, A. Satake ${ }^{3}$, K. Matsui $^{1}$, H. Sano ${ }^{1}$. ${ }^{1}$ Division of Rheumatology, Department of Internal Medicine, Hyogo College of Medicine, Nishinomiya, Hyogo; ${ }^{2}$ Department of Pharmacy, Hyogo University of Health Sciences, Kobe, ${ }^{3} 1$ st Department of Internal Medicine, Kansai Medical University, Hirakata, Japan

Background: Interleukin-2 (IL-2) induces regulatory T cells (Tregs) and reduces disease activity such as graft versus-host disease and systemic lupus erythematosus. IL-2/anti-IL-2 monoclonal antibody immune complex (IL-2IC) increases the half-life of IL-2 in vivo and specifically induces Tregs. We previously demonstrated that administration of IL-2IC suppressed collagen-induced arthritis $(\mathrm{CIA})$ in mice (EULAR 2015).

Objectives: To clarify complex regulatory network of IL-2IC in autoimmune arthritis, we examined the suppression mechanism of IL-2IC induced Tregs to Th1 and Th17.

Methods: Male DBA/1 mice were immunized by injection of $200 \mu \mathrm{g}$ of Type II collagen emulsified with an equal volume of complete Freud adjuvant intradermally at the base of the tail of mice (first immunization). Second immunization was given 21 days after first immunization. IL-2ICs were prepared by mixing $5 \mu \mathrm{g}$ of anti-IL-2 antibody (clone JES6-1D) with $1 \mu \mathrm{g}$ of mouse IL-2 for 15 minutes. The mice were

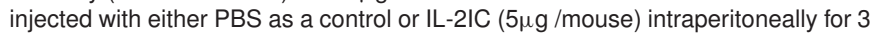
days. Mouse paws were scored for arthritis using a macroscopic scoring system ranging from 0 to $4(0$, no swelling or redness; 1 , swelling/redness of paw or one joint; 2 , two joints involved; 3 , more than two joints involved; and 4 , severe arthritis of the entire paw and joints). The arthritic score for each mouse is the sum of the scores of all four paws. Peripheral blood cells were stained with anti-CD25 (PC61), anti-CD4 (RM4-5), anti-Foxp3 (FJK-16s) and CD4+CD25+Foxp3+ Tregs were analyzed by flow cytometry. Th1 and Th17 cells infiltrating in the synovium were examine by immunohistochemistry stained with anti-IFN-g and IL-17 mAb. CD4+CD25+ Treg cells were analyzed for suppressive activity against proliferation of effector CD4+ T cells. For intracellular cytokine staining, spleen cells which were removed in day 28 , were stimulated with PMA, ionomycin, and breferdin for 6 hours and intracellular cytokine staining were performed by using anti-IFN- $\gamma$, anti-IL-10, anti-IL-17, and analyzed by flow cytometry.

Results: To define the effects of IL-2IC on established CIA, IL-2IC was administered for 3 days from day 21 to day 23 after the first immunization (day 0 to day 2 after the second immunization) of CIA. To define the effect of IL-2IC on early stages of disease induction we administered IL-2IC from day 0 to day 2 after first immunization. We observed a significant decrease in both the incidence and severity of arthritis in these CIA mice. Injection of IL-2IC effectively elicited more than 2-fold expansion of CD4+CD25+Foxp3+ Tregs in peripheral blood cells than control mice. Th1 and Th17 cells infiltrations in the synovium were significantly inhibited by IL-2IC treatment. In vitro suppression assay demonstrated significant augmentation of the suppressive capacity of CD4+CD25+Treg cells in IL-2IC treated mice. Intracellular cytokine staining revealed that IL-10 production by CD4+ cells in IL-2IC treated spleen increased four folds than in controls, and IFN- $\gamma$-producing helper T cells (Th1) and IL-17-producing helper T cells (TH17) were significantly decreased.

Conclusions: These observations indicate that IL-2IC not only induce Tregs, but also augments Treg function by enhancing IL-10 production. Thereby Tregs suppress Th1 and Th17 cells.

Disclosure of Interest: None declared

DOI: 10.1136/annrheumdis-2017-eular.4644 